\title{
Estudos de associação entre transtorno obsessivo-compulsivo e genes candidatos: uma revisão
}

\author{
Studies of association between the obsessive-compulsive disorder and \\ candidate genes: a review
}

Felipe Filardi da Rocha, Karla Cristhina Alves de Sousa, Antônio Lúcio Teixeira, Leonardo F. Fontenelle, Marco Aurélio Romano-Silva e Humberto Corrêa

\begin{abstract}
Resumo
Objetivo: Nos últimos anos, o papel dos genes dos sistemas serotoninérgicos e dopaminérgicos tem sido sistematicamente investigado em pacientes com transtorno obsessivo-compulsivo (TOC), uma vez que esses neurotransmissores apresentam uma provável implicação na fisiopatologia do TOC. Este artigo objetiva revisar os principais resultados de estudos de associação entre genes candidatos e TOC. Métodos: Revisão da literatura na base de dados Medline até agosto de 2006, utilizando as palavras-chave obsessive-compulsive disorder (OCD) e/ou gene(s), polymorphism(s), genetics. Resultados: Inúmeros estudos têm apresentado resultados negativos ao compararem pacientes com TOC e controles, entretanto resultados positivos têm sido observados em pacientes com TOC com características clínicas particulares (sexo, idade de início, dimensão ou gravidade dos sintomas obsessivos ou compulsivos e presença de tiques). Conclusão: Para garantir a continuidade do avanço de estudos genéticos, é necessária a identificação de subgrupos homogêneos de pacientes com TOC. Diante desses grupos, será possivvel delinear endofenótipos confiáveis que permitam explorar de forma mais específica a contribuição dos diferentes genes na patogênese da doença.

Palavras-chave: transtorno obsessivo-compulsivo, genes, polimorfismo genético.
\end{abstract}

\begin{abstract}
Objective: The obsessive compulsive-disorder (OCD) is a psychiatric disorder characterized by the presence of obsessions and compulsions. Its prevalence is of approximately $2 \%-3 \%$ in the general population. In the last years, genes of the serotoninergic and dopaminergic systems have been investigated as these neurotransmitters are probably involved in the pathophysiology of the OCD. This article aims at revising the results of studies of association between candidate genes and OCD. Methods: Review of the literature in the Medline database until August of 2006, using the key words: obsessive-compulsive disorder, OCD and/or gene(s), polymorphism(s), genetics. Results: A series of studies presented negative results when comparing OCD patients and controls. Nevertheless, positive results have been observed, when studying among OCD patients, distinct clinical features (gender, age of beginning, dimension and/or severity of the obsessive and/or compulsive symptoms, presence of tics). Conclusion: For the advance of genetic studies in $O C D$, it would be necessary to identify homogeneous subgroups of OCD patients. Based on these subgroups, it may be possible to define reliable endophenotypes that could lead to a more rational search for genes possibly involved in OCD pathogenesis. Key words: obsessive-compulsive disorder, genes, polymorphism.
\end{abstract}

Hospital das Clínicas da Universidade Federal de Minas Gerais (HC/UFMG) (Rocha FF, Sousa KCA) Instituto de Ciências Biológicas da UFMG (ICB/UFMG) (Rocha FF, Romano-Silva MA) Faculdade de Medicina da UFMG (Teixeira AL, Corrêa H) Faculdade de Medicina da Universidade Federal do Rio de Janeiro (FM/UFRJ) (Fontenelle LF) ICB/UFMG. 


\section{Introdução}

Os sintomas do transtorno obsessivo-compulsivo (TOC) são descritos na literatura médica desde o século XIX, mas provavelmente sempre acompanharam o ser humano. Também há muito se percebe que o TOC teria um componente familiar, que possivelmente seria hereditário. Pierre Janet, por exemplo, na sua descrição sobre a psicastenia, em 1903, observou uma freqüência de $28 \%$ dessa condição entre os genitores dos pacientes (Pauls et al., 1991).

Hoje há muitas evidências provenientes de estudos de epidemiologia genética, particularmente estudos familiares e com gêmeos, de que o TOC não apenas se agrega em famílias, mas também que seria, pelo menos em parte, geneticamente determinado (Pauls e Alsobrook, 1999; Nestadt et al., 2000; van Grootheest et al., 2005).

A partir dessas evidências, estudos têm sido realizados com o objetivo de se determinar qual, ou, mais provavelmente, quais seriam os genes associados ao TOC. Duas principais estratégias são usadas para esse propósito: os estudos de escaneamento genômico global e os de associação.

Na primeira abordagem, objetiva-se identificar ligações existentes entre TOC e marcadores genéticos em famílias com múltiplos indivíduos afetados e, assim, encontrar regiões cromossômicas onde possam existir genes de suscetibilidade para esse transtorno. Esses estudos são mais raros e, recentemente, foi publicado o maior deles, que encontrou como candidatas as regiões cromossômicas $1 q, 3 q, 6 q, 7 p$ e 15q (Shugart et al., 2006).

A segunda abordagem, muito mais comum no TOC, são os chamados estudos de associação ou estudos com genes candidatos. Nesse tipo de estudo, as freqüências dos diferentes alelos de um determinado gene candidato são comparadas entre um grupo de casos e um grupo-controle. Esses genes candidatos são geralmente escolhidos por codificarem proteínas que, do ponto de vista neurobiológico, ou a partir de considerações teóricas sobre a fisiopatologia do TOC, podem estar associadas a esse transtorno. Significativo número de estudos utiliza também os chamados métodos baseados em famílias, ou seja, o método de risco relativo de haplótipos (HRR) e o teste de desequilíbrio de transmissão (TDT) (Thapar et al., 1999). No HRR, para determinado marcador, compara-se a freqüência dos alelos parentais transmitidos ao filho afetado com a freqüência dos alelos parentais não transmitidos. Já o TDT, um teste de ligação, avalia a segregação dos alelos. Qualquer que seja a freqüência nos pais, a chance de transmissão de cada alelo é de 50\%. Portanto verifica-se ligação quando há uma distorção dessa segregação, ou seja, transmissão preferencial de um dos alelos parentais.

Nesta revisão narrativa, nosso objetivo foi descrever e avaliar criticamente os estudos de associação entre polimorfismos de genes candidatos e TOC publicados até o momento.

\section{Métodos}

Realizamos uma busca na base de dados Medline utilizando os seguintes termos de procura: obsessive-compulsive disorder (OCD) elou gene(s), polymorphism(s), genetic(s).
Consideramos artigos nas línguas portuguesa, inglesa, espanhola, italiana, francesa e alemã até agosto de 2006. Também realizamos uma revisão suplementar da literatura a partir das referências citadas pelos artigos selecionados.

Com base nos resultados obtidos, 59 artigos foram selecionados para esta revisão. Desses, 42 apresentaram metodologia baseada na comparação entre casos e controles, e 22 trabalhos com famílias utilizando o TDT e/ou HRR.

\section{Resultados}

\section{Estudos envolvendo a via serotoninérgica}

A observação de que a clomipramina apresenta bons resultados no tratamento do TOC foi a primeira indicação de que a serotonina poderia exercer papel nesse transtorno. A clomipramina tem grande afinidade pelo sítio de recaptura de serotonina $(5 \mathrm{HT})$ e baixa afinidade pelo sítio correspondente da noradrenalina (NA). Porém seu metabólito desmetilclorimipramina inibe predominantemente a recaptura de NA. Logo, a clomipramina não pode ser considerada verdadeiro inibidor seletivo da recaptação de serotonina (ISRS) quando administrada cronicamente (Zohar et al., 1988). Contudo outras evidências fortalecem a hipótese da mediação serotonérgica na ação farmacológica anti-TOC. Por exemplo, alguns estudos demonstraram que antidepressivos com maior ação noradrenérgica são menos eficazes que a clomipramina no TOC. Essa diferença contrasta com a equivalência da ação terapêutica de drogas predominantemente serotoninérgicas e noradrenérgicas no transtorno depressivo unipolar. Posteriormente, os ISRSs, como fluoxetina, fluvoxamina e sertralina, que, mesmo apresentando metabólitos sem ação na recaptação de NA, mostraram eficácia no tratamento do TOC (Zohar et al., 1992).

\section{Gene do transportador de 5HT}

O gene do transportador de serotonina é de particular interesse, pois se postula que a magnitude e a duração da atividade serotoninérgica sejam reguladas pelo transportador de serotonina (5HTT), que controla a recaptura de serotonina na fenda sináptica. O gene codificador do 5 HTT está localizado no cromossomo 17 (17q11.1-q12) e tem uma seqüência de $31 \mathrm{~kb}$, que é organizada em 14 éxons (Lesch et al., 1996). $\mathrm{Na}$ região promotora desse gene há duas variantes alélicas, uma longa (L) e outra curta (S), que diferem entre si por 44 pares de base. Essa mutação leva a alterações funcionais, tendo sido demonstrado que a variante longa do transportador capta cerca de duas vezes mais serotonina do que a curta (Collier et al., 1996).

A maioria dos estudos tem obtido resultados negativos, visto que apenas quatro trabalhos demonstraram associações estatisticamente significativas entre casos e controles (Tabela 1).

Outra abordagem adotada é a procura de associações, não apenas com o diagnóstico de TOC, mas com características clínicas específicas desse transtorno. Ao se correlacionar a resposta à fluvoxamina e ao genótipo do paciente, achados significativos foram encontrados 
apenas no subgrupo constituído por pacientes sem tiques (Di Bella et al., 2002). No mesmo ano, em um subgrupo de pacientes com tiques, encontrou-se associação entre os genótipos L/L, com maiores escores para rituais de contagem e repetição pela escala Y-BOCS (Cavallini et al., 2002). Posteriormente observou-se que o alelo L está relacionado a sintomas das esferas religiosa e somática (Kim et al., 2005), e que o alelo S e o genótipo S/S estão relacionados a obsessões de simetria e compulsões de contagem, repetição e arrumação (Hasler et al., 2006). Diferenças entre os sexos também já foram observadas, com os casos do sexo feminino apresentando maior freqüência do alelo S (Denys et al., 2006).

\section{Genes dos receptores $5 \mathrm{HT}$}

Nos últimos anos, uma enorme quantidade de informações sobre a identificação e a função dos receptores serotoninérgicos foi produzida. Até o momento já foram identificadas sete classes de receptores $5 \mathrm{HT}$ (5HT-1 a 5HT-7), perfazendo um total de 15 subtipos (por exemplo, 5HT-2A e 5HT-2C) (Graeff, 1997). O papel dos genes dos receptores $5 \mathrm{HT} 2 \mathrm{~A}, 5 \mathrm{HT} 2 \mathrm{C}, 5 \mathrm{HT} 1 \mathrm{Db}$ e $5 \mathrm{HT} 1 \mathrm{~B}$ no TOC já foi estudado, mas os resultados são inconclusivos (Tabela 2).

Assim, como observado nos estudos envolvendo 0 gene do 5HTT, existem evidências correlacionando alguns polimorfismos com determinadas diferenças clínicas:

- maior gravidade da doença (Tot et al., 2003; Levitan et al., 2006);

- maiores escores de obsessões pela Y-YBOCS (Camarena et al., 2004);

- início precoce dos sintomas e história familiar positiva (Denys et al., 2006);

- distinção pelo sexo (Lochner et al., 2004).

\section{Estudos envolvendo a enzima triptofano-hidroxilase}

Outro candidato é o gene que codifica a enzima triptofano-hidroxilase, a qual a biossíntese da serotonina (Delorme et al., 2006). Estudos de caso-controle com os polimorfismos T1095C (Han et al., 1999; Frisch et al., 2000) e R441H (Delorme et al., 2006) foram negativos, assim como um estudo de família com polimorfismo de nucleotídeo simples (SNP) (rs1800532) (Walitza et al., 2004). O único resultado positivo foi em um estudo familiar com dois SNPs (rs4570625 e rs4565946), mostrando significativa transferência do haplótipo G-C entre os casos (Mossner et al., 2005). Portanto percebe-se que, dos poucos estudos que avaliaram o gene da enzima triptofano-hidroxilase, não se estabeleceu claramente um alvo genético definido.

\section{Estudos envolvendo a via dopaminérgica}

O sistema dopaminérgico apresenta pelo menos cinco subtipos de receptores, os quais se expressam em quantidades variáveis nessas vias (conhecidos como D1 a D5 ou DRD1 a DRD5) (Frisch et al., 2000).

Há várias evidências de que alterações genéticas, as quais determinam disfunção dopaminérgica nos núcleos da base, possam estar envolvidas na etiologia de sintomas obsessivos-compulsivos (Tabela 3). Essas alterações reforçam a relação clinicofamiliar entre o TOC e a síndrome de Tourette (Graybiel e Rauch, 2000). De fato, o grupo de indivíduos afetados por TOC e tiques deve representar um subtipo genético mais dopaminérgico e diferente daqueles que não apresentam tiques (Nicolini et al., 1996; Cruz et al., 1997; Nicolini et al., 1998; Millet et al., 2003).

\section{Estudos envolvendo a enzima catecol-O-metiltransferase}

A catecol-O-metiltransferase (COMT) está envolvida na metabolização de catecolaminas, como a dopamina e a noradrenalina. Há duas formas dessa enzima: uma solúvel encontrada em vários tecidos, e outra ligada à membrana plasmática. A forma solúvel apresenta atividades enzimáticas diferentes devido à substituição de um nucleotídeo (uma citosina por uma adenina) na posição 158 do gene que a codifica. Essa substituição nucleotídica acarreta mudança de aminoácido, uma valina (alta atividade enzimática - alelo $\mathrm{H}$ ) por uma metionina (baixa atividade - alelo $L$ ), na estrutura protéica dessa enzima (Karayiorgou et al., 1997).

Os trabalhos têm sido quase unânimes ao escolherem esse polimorfismo para se investigarem associações com o TOC, com vários resultados positivos baseados na distinção dos pacientes por sexo (Tabela 4).

Somente um trabalho avaliou um polimorfismo diferente (substituição $\mathrm{C} / \mathrm{T}$ na região promotora do gene adjacente ao ERE6), mas sem encontrar associações estatisticamente significativas (Kinnear et al., 2001).

\section{Estudos envolvendo a enzima monoamina oxidase A}

A monoamina oxidase (MAO) é uma enzima que degrada uma série de aminas biogênicas, entre elas a serotonina, a adrenalina, a noradrenalina e a dopamina. Os subtipos A e B podem ser distinguidos de acordo com suas propriedades bioquímicas e farmacológicas (Karayiorgou et al., 1999).

Em relação ao polimorfismo EcoRV não foram observadas diferenças significativas entre casos e controles (Camarena et al., 2001; Hemmings et al., 2003; Lochner et al., 2004). No entanto, ao distinguir os pacientes por sexo, resultados positivos foram observados (Camarena et al., 2001; Lochner et al., 2004). Além disso, houve associação estatisticamente significativa entre o polimorfismo Fnu $4 \mathrm{H} 1$ no éxon 8 do gene da MAO-A (vinculado ao aumento de sua atividade enzimática) e pacientes do sexo masculino com co-morbidade e transtorno depressivo maior (Karayiorgou et al., 1999).

\section{Estudos com outras vias de neurotransmissão}

Outras vias têm sido estudadas com resultados incertos para se estabelecer o seu verdadeiro papel na fisiopatologia do TOC, apesar de serem considerados alvos promissores de futuros estudos (Tabela 5 ). 
Tabela 1. Estudos que avaliaram o gene do 5HTT

\begin{tabular}{|c|c|c|c|c|c|}
\hline \multirow{2}{*}{ Gene } & \multirow{2}{*}{ Polimorfismo } & \multicolumn{2}{|c|}{ Caso-controle } & \multicolumn{2}{|r|}{ Família } \\
\hline & & Positivo & Negativo & Positivo & Negativo \\
\hline $5 \mathrm{HTT}$ & SLC6A4 & $\begin{array}{l}\text { Bengel et al., 1999; } \\
\text { Baca-Garcia et al., } 2005\end{array}$ & $\begin{array}{l}\text { Altemus et al., 1996; Billiett et al., } \\
\text { 1997; Frisch et al., 2000; Kinnear } \\
\text { et al., 2000; Camarena et al., } \\
\text { 2001; Di Bella et al., 2002; Cha- } \\
\text { bane et al., 2004; Meira-Lima et } \\
\text { al., 2004; Kim et al., 2005; Denys } \\
\text { et al., } 2006\end{array}$ & $\begin{array}{l}\text { McDougle et al. } \\
\text { 1998; Hu et al., } \\
2006\end{array}$ & $\begin{array}{l}\text { Camarena et al., 2001; } \\
\text { Walitza et al., 2004; } \\
\text { Chabane et al., } 2004\end{array}$ \\
\hline
\end{tabular}

Tabela 2. Estudos que avaliaram os genes dos receptores 5HT

\begin{tabular}{|c|c|c|c|c|c|}
\hline \multirow{2}{*}{ Gene } & \multirow{2}{*}{ Polimorfismo } & \multicolumn{2}{|c|}{ Caso-controle } & \multicolumn{2}{|c|}{ Família } \\
\hline & & Positivo & Negativo & Positivo & Negativo \\
\hline \multirow[t]{3}{*}{$5 \mathrm{HT} 2 \mathrm{~A}$} & $\mathrm{~T} 102 \mathrm{C}$ & & $\begin{array}{l}\text { Nicolini et al., 1996; Frisch et al., 2000; } \\
\text { Tot } \\
\text { et al., 2003; Hemmings et al., 2003; } \\
\text { Hemmings et al., 2004; Meira-Lima et } \\
\text { al., } 2004\end{array}$ & & \\
\hline & G1438A & $\begin{array}{l}\text { Enoch et al., 2001; Walitza } \\
\text { et al., } 2002\end{array}$ & Enoch et al., 1998 & & \\
\hline & C516T & Meira-Lima et al., 2004 & & & \\
\hline $5 \mathrm{HT} 2 \mathrm{C}$ & Cys23-Ser23 & & Cavalini et al., 1998; Frisch et al., 2000 & & \\
\hline $5 \mathrm{HT} 1 \mathrm{Db}$ & G861C & & $\begin{array}{l}\text { Lochner et al., 2004; Hemmings et al., } \\
\text { 2004; Levitan et al., } 2006\end{array}$ & $\begin{array}{l}\text { Mundo et al., 2000; } \\
\text { Mundo et al., } 2002\end{array}$ & $\begin{array}{l}\text { Di Bella et al., 2002; } \\
\text { Camarena et al., } \\
2004\end{array}$ \\
\hline 5HT1B & ND & & Denys et al., 2006 & & Walitza et al., 2004 \\
\hline
\end{tabular}

$\mathrm{ND}=$ Não-disponivel.

Tabela 3. Estudos envolvendo a via dopaminérgica

\begin{tabular}{|c|c|c|c|c|c|}
\hline \multirow{2}{*}{ Gene } & \multirow{2}{*}{ Polimorfismo } & \multicolumn{2}{|r|}{ Caso-controle } & \multicolumn{2}{|c|}{ Família } \\
\hline & & Positivo & Negativo & Positivo & Negativo \\
\hline \multirow{2}{*}{ DRD2 } & TaqlA & & $\begin{array}{l}\text { Nicolini et al., 1996*; Billiett et al., 1998; } \\
\text { Nicolini et al., 1998*; Denys et al., } 2006\end{array}$ & & \\
\hline & $\begin{array}{l}\text { Polimorfismos nos } \\
\text { éxons } 4,5 \text { e } 6\end{array}$ & & Novelli et al., 1994 & & \\
\hline DRD3 & Mscl & & $\begin{array}{l}\text { Catalano et al., 1994; Nicolini et al., } \\
\text { 1996; Billiett et al., } 1998\end{array}$ & & \\
\hline \multirow[t]{2}{*}{ DRD4 } & VNTR & $\begin{array}{l}\text { Billiett et al., 1998; } \\
\text { Hemmings et al., 2003; } \\
\text { Hemmings et al., 2004; } \\
\text { Camarena et al., 2006 }\end{array}$ & Cruz et al., 1997*; Nicolini et al., 1998* & $\begin{array}{l}\text { Millet et al., } \\
2003^{*}\end{array}$ & $\begin{array}{l}\text { Camarena et al., } \\
2006\end{array}$ \\
\hline & $\begin{array}{l}\text { Mutação nula } \\
\text { no éxon } 1\end{array}$ & & Di Bella et al., 1996 & & \\
\hline DAT & $\begin{array}{l}\text { Polimorfismo carac- } \\
\text { terizado por uma } \\
\text { repetição de } 40 \mathrm{bp}\end{array}$ & & $\begin{array}{l}\text { Billiett et al., 1998; Frisch et al., 2000; } \\
\text { Hemmings et al., 2003; Hemmings et } \\
\text { al., } 2004\end{array}$ & & \\
\hline
\end{tabular}

*Estudos que demonstraram associações positivas ao distinguir os pacientes em dois subgrupos: com e sem tiques. DAT: transportador de dopamina. 
Tabela 4. Estudos envolvendo o polimorfismo do códon 158 da COMT

\begin{tabular}{|c|c|c|}
\hline Autores & Estudo & Resultados \\
\hline Karayiorgou et al., 1997 & Caso-controle & $\begin{array}{l}\text { Genótipo } L / L \text { é fator de risco; maior freqüência do alelo } L \text { em } \\
\text { casos do sexo masculino }\end{array}$ \\
\hline Karayiorgou et al., 1999 & Família & $\begin{array}{l}\text { Genótipo } L / L \text { é fator de risco; maior freqüência do alelo } L \text { em } \\
\text { casos do sexo masculino }\end{array}$ \\
\hline Schindler et al., 2000 & Família & Tendência a homozigose em pacientes com TOC \\
\hline Niehaus et al., 2001 & Caso-controle & Genótipo H/L mais freqüente entre os casos \\
\hline Alsobrook et al., 2002 & Família & Maior freqüência do alelo $L$ em casos do sexo feminino \\
\hline Erdal et al., 2003 & Caso-controle & $\begin{array}{l}\text { Casos com alelo } L \text { apresentaram maiores escores de insight } \\
\text { (menos insight) }\end{array}$ \\
\hline Meira-Lima et al., 2004 & Caso-controle & Sem associações significativas \\
\hline Poyurovsky et al., 2005 & Caso-controle & Sem associações significativas \\
\hline Denys et al., 2006 & Caso-controle & Menor freqüência do alelo L em casos do sexo masculino \\
\hline
\end{tabular}

COMT: Catecol-O-metiltransferase; TOC: transtorno obsessivo-compulsivo.

Tabela 5. Estudos envolvendo outras vias de neurotransmissão

\begin{tabular}{|c|c|c|c|}
\hline Autores & Gene e/ou polimorfismos & Estudo & Resultados \\
\hline Hall et al., 2003 & $\begin{array}{l}\text { BDNF - uma série de SNPs, } \\
\text { inclusive Val66Met }\end{array}$ & Família & Associações significativas \\
\hline Urraca et al., 2004 & $\begin{array}{l}\text { Receptor opióide Mu - polimorfis- } \\
\text { mos C17T e A118G }\end{array}$ & Família & $\begin{array}{l}\text { Ausência de associações } \\
\text { significativas }\end{array}$ \\
\hline Delorme et al., 2004 & $\begin{array}{l}\text { Receptor glutaminérgico GRIK2 } \\
\text { - dois SNPs; receptor glutaminér- } \\
\text { gico GRIK3 - um SNP }\end{array}$ & Caso-controle e família & Associações significativas \\
\hline Arnold et al., 2004 & $\begin{array}{l}\text { Receptor glutaminérgico GRIN2B } \\
\text { - polimorfismo 5072T/G }\end{array}$ & Família & Associações significativas \\
\hline Zai et al., 2005 & $\begin{array}{l}\text { Receptor GABAérgico GABBR1 - } \\
\text { polimorfismos A7265G, C10497G, } \\
\text { A33795G, Ser-491-Ser-T1473C, } \\
\text { Phe-659-Phe-T1977C }\end{array}$ & Família & $\begin{array}{l}\text { Ausência de associações } \\
\text { significativas }\end{array}$ \\
\hline Dickel et al., 2006 & $\begin{array}{l}\text { Transportador glutaminérgico } \\
\text { SLC1A1 - nove SNPS }\end{array}$ & Família & Associações significativas \\
\hline Arnold et al., 2006 & $\begin{array}{l}\text { Transportador glutaminérgico } \\
\text { SLC1A1 - nove SNPS }\end{array}$ & Família & Associações significativas \\
\hline
\end{tabular}

SNP = Polimorfismo de nucleotídeo simples.

\section{Discussão}

O estudo da etiopatogênese do TOC ainda está no início. Mesmo em relação à genética, intensamente investigada nos últimos anos, os resultados são, na maioria das vezes, negativos, sendo contraditórias muitas associações positivas. Dessa forma, nenhum desses genes pode ser considerado necessário ou suficiente para o desenvolvimento do TOC.

Interferências das co-morbidades ou das fenocópias (manifestações semelhantes à doença em estudo, mas com origem não-genética) e da diferença étnica das amostras avaliadas podem conduzir a resultados falsos. Resultados enviesados também podem advir da própria complexidade etiológica da enfermidade, que teria uma heterogeneidade genética, isto é, um mesmo fenótipo resultaria de diferentes genes afetados em diferentes famílias.

Gottesman e Hanson (2005) fizeram a seguinte citação: "um dos obstáculos primários ao progresso em conectar as contribuições genotípicas aos muitos fenótipos humanos é que os traços submetidos a análises genéticas carecem de significado biológico". Eles argumentam que, ao estudarmos o produto de um processo que pode ter levado décadas, "nós freqüentemente temos muito 'feno' e insuficiente 'geno' para fazer sentido do traço" (Gottesman e Hanson, 2005).

Como os diagnósticos psiquiátricos são feitos em nível de sintomas clínicos, é provável que o caminho do genótipo/fenótipo seja longo e complexo, com muitos exemplos de convergência e divergência. Dessa maneira, é tentador estudar 
traços que são intermediários entre a apresentação clínica e seu fundamento genético. Esses traços ou endofenótipos são mais simples do ponto de vista genético, provavelmente por estarem associados a menos lócus genéticos (Gottesman e Gould, 2003). Isso pelo fato de que, ao reduzir a complexidade do marcador, também deverá ser reduzida a complexidade de sua base genética.

Ao invés de se procurar por genes codificando transtornos complexos, a pesquisa de endofenótipos procura por genes de traços simples, idealmente monogênicos, que acompanham as doenças e provavelmente contribuem para sua fisiopatologia. Se os fenótipos associados a um transtorno são muito restritos e representam fenômenos mais elementares, o número de genes necessários para produzir variações nesses traços pode ser menor do que aqueles envolvidos na produção de uma entidade psiquiátrica complexa (McQueen et al., 2005).

Ao se considerar como base os estudos revisados, nota-se a necessidade de se identificar fenótipos intermediários ou endofenótipos, características essas que podem proporcionar maior objetividade na seleção de genes candidatos na fisiopatologia do TOC. Um passo importante para definir endofenótipos clinicamente relevantes seria a busca de subtipos de TOC. Assim, desde os primeiros estudos realizados no final da década passada, fatores como época de aparecimento dos sintomas (TOC de início precoce vs. tardio), distribuição familiar, presença de tiques e sexo dos pacientes vêm se firmando como subtipos concretos para esse fim. Além deles, estão sendo obtidos resultados significativos em relação à intensidade e às características dos sintomas, com as principais dimensões sintomáticas (contaminação e limpeza; colecionismo; simetria, ordem, contagem e arranjo; sexo e religião; agressão; obsessões e compulsões diversas), aparentando fazerem parte de subtipos clínicos distintos. Também se deve mencionar que, apesar de haver poucos estudos, características como maior ou menor insight da doença e a presença de outras co-morbidades médicas também podem, no futuro, integrar a lista de subtipos plausíveis nas investigações a respeito da etiologia do TOC.

\section{Conclusão}

O futuro do estudo da etiopatogênese do TOC envolve, certamente, a definição de possíveis endofenótipos em que a heterogeneidade clínica esteja reduzida. Além disso, são necessárias reproduções dos resultados positivos em amostras de pacientes provenientes de diferentes países antes de se aceitar um agente ambiental e/ou um gene candidato como fator de suscetibilidade.

\section{Referências}

Alsobrook JP, Zohar AH, Leboyer M, Chabane N, Ebstein RP, Pauls $\mathrm{DL}$. Association between the COMT locus and obsessivecompulsive disorder in females but not males. Am J Med Genet, 114: 116-20, 2002.

Altemus M, Murphy DL, Greenberg B, Lesch KP. Intact coding region of the serotonin transporter gene in obsessive-compulsive disorder. Am J Med Genet, 67: 409-11, 1996.

Arnold PD, Rosenberg DR, Mundo E, Tharmalingam S, Kennedy JL, Richter MA. Association of a glutamate (NMDA) subunit receptor gene (GRIN2B) with obsessive-compulsive disorder: a preliminary study. Psychopharmacology, 174: 530-8, 2004.

Arnold PD, Sicard T, Burroughs E, Richter MA, Kennedy JL. Glutamate transporter gene SLC1A1 associated with obsessive-compulsive disorder. Arch Gen Psychiatry, 63: 769-76, 2006.

Baca-Garcia E, Salgado BR, Segal HD, Lorenzo CV, Acosta MN, Romero MA, et al. A pilot genetic study of the continuum between compulsivity and impulsivity in females: the serotonin transporter promoter polymorphism. Prog Neuropsychophar Biol Psychiatry, 29: 713-7, 2005

Bengel D, Greenberg BD, Cora-Locatelli G, Altemus M, Heils A, Li Q, et al. Association of the serotonin transporter promoter regulatory region polymorphism and obsessive-compulsive disorder. Mol Psychiatry, 4: 463-6, 1999.

Billett EA, Richter MA, King N, Heils A, Lesch KP, Kennedy JL. Obsessive-compulsive disorder, response to serotonin reuptake inhibitors and the serotonin transporter gene. Mol Psychiatry, 2: 403-6, 1997.
Billett EA, Richter MA, Sam F, Swinson RP, Dai XY, King N, et al. Investigation of dopamine system genes in obsessive-compulsive disorder. Psychiatr Genet, 8: 163-9, 1998.

Camarena B, Aguilar A, Loyzaga C, Nicolini H. A family-based association study of the 5-HT-1Dbeta receptor gene in obsessivecompulsive disorder. Int J Neuropsychopharmacol, 7: 49-53, 2004.

Camarena B, Loyzaga C, Aquilar A, Weissbecker K, Nicolini H. Association study between the dopamine receptor $D(4)$ gene and obsessive-compulsive disorder. Eur Neuropsychoph, 2006. Epub ahead of print.

Camarena B, Rinetti G, Cruz C, Gomez A, de La Fuente JR, Nicolini $\mathrm{H}$. Additional evidence that genetic variation of MAO-A gene supports a gender subtype in obsessive-compulsive disorder. Am J Med Genet, 105: 279-82, 2001.

Camarena B, Rinetti G, Cruz C, Hernandez S, de la Fuente JR, Nicolini $H$. Association study of the serotonin transporter gene polymorphism in obsessive-compulsive disorder. Int $\mathrm{J}$ Neuropsychoph, 4: 269-72, 2001.

Carey G, Gottesman II. Twin and family studies of anxiety, phobic and obsessive disorders. In: Klien DF, Rabkin J, editors. Anxiety: new research and changing concepts. New York: Raven Press, 1981. p. 117-36.

Catalano M, Sciuto G, Di Bella D, Novelli E, Nobile M, Bellodi L. Lack of association between obsessive-compulsive disorder and the dopamine D3 receptor gene: some preliminary considerations. Am J Med Genet, 54: 253-5, 1994. 
Cavallini MC, Di Bella D, Pasquale L, Henin M, Bellodi L. 5HT2C CYS23/ SER23 polymorphism is not associated with obsessive-compulsive disorder. Psychiatry Res, 77: 97-104, 1998.

Cavallini MC, Di Bella D, Siliprandi F, Malchiodi F, Bellodi L. Exploratory factor analysis of obsessive-compulsive patients and association with 5-HTTLPR polymorphism. Am J Med Genet, 114: 347-53, 2002.

Cavalini MC, Pasquale L, Bellodi L, Smeraldi E. Complex segregation analysis for obsessive-compulsive disorder and related disorders. Am J Med Genet, 88: 38-43, 1999.

Chabane N, Millet B, Delorme R, Lichtermann D, Mathieu F, Laplanche JL, et al. Lack of evidence for association between serotonin transporter gene (5-HTTLPR) and obsessive-compulsive disorder by case control and family association study in humans. Neurosci Lett, 363 : 154-6, 2004

Collier DA, Stober G, Li T, Heils A, Catalano M, Di Bella D, et al. A novel functional polymorphism within the promoter of the serotonin transporter gene: possible role in susceptibility to affective disorders. Mol Psychiatry, 1: 453-60, 1996.

Cruz C, Camarena B, King N, Paez F, Sidenberg D, de la Fuente JR, et al. Increased prevalence of the seven-repeat variant of the dopamine D4 receptor gene in patients with obsessive-compulsive disorder with tics. Neurosci Lett, 231: 1-4, 1997.

Delorme R, Durand CM, Betancur C, Wagner M, Ruhrmann S, Grabe HJ, et al. No human tryptophan hydroxylase-2 gene R441H mutation in a large cohort of psychiatric patients and control subjects. Biol Psychiatry, 60: 202-3, 2006.

Delorme R, Krebs MO, Chabane N, Roy I, Millet B, Mouren-Simeoni MC, et al. Frequency and transmission of glutamate receptors GRIK2 and GRIK3 polymorphisms in patients with obsessive-compulsive disorder. Neuroreport, 15: 699-702, 2004.

Denys D, Van Nieuwerburgh F, Deforce D, Westenberg HG. Association between serotonergic candidate genes and specific phenotypes of obsessive compulsive disorder. J Affect Dis, 91: 39-44, 2006.

Denys D, Van Nieuwerburgh F, Deforce D, Westenberg H. Association between the dopamine $D(2)$ receptor Taql $A 2$ allele and low activity COMT allele with obsessive-compulsive disorder in males. Eur Neuropsychoph, 16: 446-50, 2006.

Di Bella D, Catalano M, Cichon S, Nothen MM. Association study of a null mutation in the dopamine D4 receptor gene in Italian patients with obsessive-compulsive disorder, bipolar mood disorder and schizophrenia. Psychiatr Genet, 6: 119-21, 1996.

Di Bella D, Cavallini MC, Bellodi L. No association between obsessivecompulsive disorder and the 5-HT(1Dbeta) receptor gene. Am J Psychiatry, 159: 1783-5, 2002.

Di Bella D, Erzegovesi S, Cavallini MC, Bellodi L. Obsessive-compulsive disorder, 5-HTTLPR polymorphism and treatment response. Pharmacogenomics J, 2: 176-81, 2002.

Dickel DE, Veenstra-VanderWeele J, Cox NJ, Wu X, Fischer DJ, Van Etten-Lee $\mathrm{M}$, et al. Association testing of the positional and functional candidate gene SLC1A1/EAAC1 in early-onset obsessive-compulsive disorder. Arch Gen Psychiatry, 63: 778-85, 2006.

Enoch MA, Greenberg BD, Murphy DL, Goldman D. Sexually dimorphic relationship of a 5 -HT2A promoter polymorphism with obsessivecompulsive disorder. Biol Psychiatry, 49: 385-8, 2001.

Enoch MA, Kaye WH, Rotondo A, Greenberg BD, Murphy DL, Goldman D. 5 -HT2A promoter polymorphism -1438G/A, anorexia nervous, and obsessive-compulsive disorder. Lancet, 351: 1785-6, 1998.

Erdal ME, Tot S, Yazici K, Yazici A, Herken H, Erdem P, et al. Lack of association of catechol-O-methyltransferase gene polymorphism in obsessive-compulsive disorder. Depress Anxiety, 18: 41-5, 2003.

Frisch A, Michaelovsky E, Rockah R, Amir I, Hermesh H, Laor N, et al. Association between obsessive-compulsive disorder and polymorphisms of genes encoding components of the serotonergic and dopaminergic pathways. Eur Neuropsychoph, 10: 205-9, 2000.

Gottesman II, Gould TD. The endophenotype concept in psychiatry: etymology and strategic intentions. Am J Psychiatry, 160: 636-45, 2003.

Gottesman II, Hanson DR. Human development: biological and genetic processes. Annu Rev Psychol, 56: 263-86, 2005.

Graeff FG. Serotonergic systems. Psychiatr Clin N Am, 20: 723-39, 1997.

Graybiel AM, Rauch SL. Toward a neurobiology of obsessive-compulsive disorder. Neuron, 28: 343-7, 2000.

Hall D, Dhilla A, Charalambous A, Gogos JA, Karayiorgou M. Sequence variants of the brain-derived neurotrophic factor (BDNF) gene are strongly associated with obsessive-compulsive disorder. Am J Hum Genet, 73: 370-6, 2003.

Han L, Nielsen DA, Rosenthal NE, Jefferson K, Kaye W, Murphy D, et al. No coding variant of the tryptophan hydroxylase gene detected in seasonal affective disorder, obsessive-compulsive disorder, anorexia nervuos, and alcoholism. Biol Psychiatry, 45: 615-9, 1999.

Hasler G, Kazuba D, Murphy DL. Factor analysis of obsessive-compulsive disorder YBOCS-SC symptoms and association with 5-HTTLPR SERT polymorphism. Am J Med Genet B Neuropsychiatr Genet, 141: 403-8, 2006.

Hemmings SM, Kinnear CJ, Lochner C, Niehaus DJ, Knowles JA, MoolmanSmook JC, et al. Early versus late-onset obsessive-compulsive disorder: investigating genetic and clinical correlates. Psychiatry Res, 128: 175-82, 2004.

Hemmings SM, Kinnear CJ, Niehaus DJ, Moolman-Smook JC, Lochner $\mathrm{C}$, Knowles JA, et al. Investigating the role of dopaminergic and serotonergic candidate genes in obsessive-compulsive disorder. Eur Neuropsychoph, 13: 93-8, 2003.

Hu XZ, Lipsky RH, Zhu G, Akhtar LA, Taubman J, Greenberg BD, et al. Serotonin transporter promoter gain-of-function genotypes are linked to obsessive-compulsive disorder. Am J Hum Genet, 78: 815-26, 2006.

Karayiorgou M, Altemus M, Galke BL, Goldman D, Murphy DL, Ott J, et al. Genotype determining low catechol-O-methyltransferase activity as a risk factor for obsessive-compulsive disorder. Proc Natl Acad Sci USA, 94: 4572-5, 1997.

Karayiorgou M, Sobin C, Blundell ML, Galke BL, Malinova L, Goldberg P, et al. Family-based association studies support a sexually dimorphic effect of COMT and MAOA on genetic susceptibility to obsessivecompulsive disorder. Biol Psychiatry, 45: 1178-89, 1999.

Kim SJ, Lee HS, Kim CH. Obsessive-compulsive disorder, factor-analyzed symptom dimensions and serotonin transporter polymorphism. Neuropsychobiology, 52: 176-82, 2005.

Kinnear CJ, Niehaus DJ, Moolman-Smook JC, du Toit PL, van Kradenberg $\mathrm{J}$, Weyers JB, et al. Obsessive-compulsive disorder and the promoter region polymorphism (5-HTTLPR) in the serotonin transporter gene (SLC6A4): a negative association study in the Afrikaner population. Int J Neuropsychopharmacol, 3: 327-31, 2000.

Kinnear CJ, Niehaus DJ, Seedat S, Moolman-Smook JC, Corfield VA, Malherbe G, et al. Obsessive-compulsive disorder and a novel polymorphism adjacent to the oestrogen response element (ERE 6) upstream from the COMT gene. Psychiatr Genet, 11: 85-7, 2001.

Lenane MC, Swedo SE, Leonard H, Pauls DL, Sceery W, Rapoport J. Psychiatric disorders in first-degree relatives of children and adolescent with obsessive-compulsive disorder. J Am Acad Child Adolesc Psychiatry, 29: 407-12, 1990.

Lesch KP, Bengel D, Heils A, Sabol SZ, Greenberg BD, Perri S, et al. Association of anxiety-related traits with a polymorphism in the serotonin transporter gene regulatory region. Science, 274: 152730, 1996

Levitan RD, Kaplan AS, Masellis M, Basile VS, Richter MA, Kennedy JL. The serotonin-1Dbeta receptor gene and severity of obsessive-compulsive 
disorder in women with bulimia nervosa. Eur Neuropsychoph, 16: 1-6, 2006.

Lochner C, Hemmings SM, Kinnear CJ, Moolman-Smook JC, Corfield VA, Knowles JA, et al. Corrigendum to "gender in obsessive-compulsive disorder: clinical and genetic findings". Eur Neuropsychoph, 14: 437-45, 2004.

McDougle CJ, Epperson CN, Price LH, Gelernter J. Evidence for linkage disequilibrium between serotonin transporter protein gene (SLC6A4) and obsessive-compulsive disorder. Mol Psychiatry, 3: 270-3, 1998.

McQueen MB, Devlin B, Faraone SV, Nimgaonkar VL, Sklar P, Smoller JW, et al. Combined analysis from eleven linkage studies of bipolar disorder provides strong evidence of susceptibility loci on chromosomes 6q and 8q. Am J Hum Genet, 77: 582-95, 2005.

Meira-Lima I, Shavitt RG, Miguita K, Ikenaga E, Miguel EC, Vallada $\mathrm{H}$. Association analysis of the catechol-O-methyltransferase (COMT), serotonin transporter (5-HTT) and serotonin $2 \mathrm{~A}$ receptor (5HT2A) gene polymorphisms with obsessive-compulsive disorder. Genes Brain Behav, 3: 75-9, 2004.

Millet B, Chabane N, Delorme R, Leboyer M, Leroy S, Poirier MF, et al. Association between the dopamine receptor D4 (DRD4) gene and obsessive-compulsive disorder. Am J Med Genet B Neuropsychiatr Genet, 116: 55-9, 2003.

Mossner R, Walitza S, Geller F, Scherag A, Gutknecht L, Jacob C, et al. Transmission disequilibrium of polymorphic variants in the tryptophan hydroxylase-2 gene in children and adolescents with obsessive-compulsive disorder. Int J Neuropsychopharmacol, 7: 1-6, 2005

Mundo E, Richter MA, Sam F, Macciardi F, Kennedy JL. Is the 5$\mathrm{HT}$ (1Dbeta) receptor gene implicated in the pathogenesis of obsessive-compulsive disorder? Am J Psychiatry, 157: 1160-1, 2000.

Mundo E, Richter MA, Zai G, Sam F, McBride J, Macciardi F, et al. $5 \mathrm{HT} 1$ Dbeta Receptor gene implicated in the pathogenesis of obsessive-compulsive disorder: further evidence from a familybased association study. Mol Psychiatry, 7: 805-9, 2002.

Nestadt G, Samuels J, Riddle M, Bienvenu J, Liang KY, LaBuda M, et al. A family study of obsessive-compulsive disorder. Arch Gen Psychiatry, 57: 358-63, 2000.

Nicolini H, Cruz C, Camarena B, Orozco B, Kennedy JL, King N, et al. DRD2, DRD3 and 5HT2A receptor genes polymorphisms in obsessive-compulsive disorder. Mol Psychiatry, 1: 461-5, 1996.

Nicolini H, Cruz C, Paez F, Camarena B. Dopamine D2 and D4 receptor genes distinguish the clinical presence of tics in obsessivecompulsive disorder. Gac Med Mex, 134: 521-7, 1998.

Nicolini H, Hanna G, Baxter L, Schwartz J, Weissbacker K, Spence MA. Segregation analysis of obsessive-compulsive and related disorders: preliminary results. Ursus Med, 1: 25-8, 1991.

Niehaus DJ, Kinnear CJ, Corfield VA, du Toit PL, van Kradenburg $\mathrm{J}$, Moolman-Smook JC, et al. Association between a catecholO-methyltransferase polymorphism and obsessive-compulsive disorder in the Afrikaner population. J Affect Disord, 65: 61-5, 2001.

Novelli E, Nobile M, Diaferia G, Sciuto G, Catalano M. A molecular investigation suggests no relationship between obsessivecompulsive disorder and the dopamine D2 receptor. Neuropsychobiology, 29: 61-3, 1994.
Pauls DL, Raymond CL, Robertson MM. The genetics of obsessivecompulsive disorder. In: Zohar Y, Insel T, Rasmussen S, editors. Psychobiological aspects of OCD. Springer, p. 89-100, New York, 1991.

Pauls DL, Alsobrook II JP, Goodman W, Rasmussen S, Leckman JF. A family study of obsessive-compulsive disorder. Am J Psychiatry, 152: 76-84, 1995.

Pauls DL, Alsobrook II JP. The inheritance of obsessive-compulsive disorder. Child Adolesc Psychiatr Clin N Am, 8: 481-96, 1999.

Poyurovsky M, Michaelovsky E, Frisch A, Knoll G, Amir I, Finkel B, et al. COMT Val158Met polymorphism in schizophrenia with obsessive-compulsive disorder: a case-control study. Neurosci Lett, 389: 21-4, 2005.

Rapoport J. The neurobiology of obsessive-compulsive disorder. JAMA, 260: 2888, 1988.

Schindler KM, Richter MA, Kennedy JL, Pato MT, Pato CN. Association between homozygosity at the COMT gene locus and obsessive compulsive disorder. Am J Med Genet, 96: 721-4, 2000.

Shugart YY, Samuels J, Willour VL, Grados MA, Greenberg BD, Knowles $\mathrm{JA}$, et al. Genomewide linkage scan for obsessive-compulsive disorder: evidence for susceptibility loci on chromosomes $3 q, 7 p$, 1q, 15q, and 6q. Mol Psychiatry, 11: 763-70, 2006.

Thapar A, Holmes J, Poulton K, Harrington R. Genetic basis os attention-deficit and hyperactivity. Br J Psychiatry, 174: 105-11, 1999.

Tot S, Erdal ME, Yazici K, Yazici AE, Metin O. T102C and -1438 G/A polymorphisms of the 5-HT2A receptor gene in Turkish patients with obsessive-compulsive disorder. Eur Psychiatry, 18: 249-54, 2003.

Urraca N, Camarena B, Gomez-Caudillo L, Esmer MC, Nicolini H. Mu opioid receptor gene as a candidate for the study of obsessivecompulsive disorder with and without tics. Am J Med Genet B Neuropsychiatr Genet, 127(1): 94-6, 2004.

van Grootheest DS, Cath DC, Beekman AT, Boomsma DI. Twin studies on obsessive-compulsive disorder: a review. Twin Res Hum Genet, 8: 450-8, 2005.

Walitza S, Wewetzer C, Warnke A, Gerlach M, Geller F, Gerber G, et al. 5-HT2A promoter polymorphism -1438G/A in children and adolescents with obsessive-compulsive disorders. Mol Psychiatry, 7: 1054-7, 2002.

Walitza S, Wewetzer C, Gerlach M, Klampfl K, Geller F, Barth N, et al. Transmission disequilibrium studies in children and adolescents with obsessive-compulsive disorders pertaining to polymorphisms of genes of the serotonergic pathway. J Neural Transm, 111: 817-25, 2004.

Zai G, Arnold P, Burroughs E, Barr CL, Richter MA, Kennedy JL. Evidence for the gamma-amino-butyric acid type $B$ receptor 1 (GABBR1) gene as a susceptibility factor in obsessive-compulsive disorder. Am J Med Genet B Neuropsychiatr Genet, 134: 25-9, 2005.

Zohar J, Zohar-Kadouch RC, Kindler S. Current concepts in the pharmacological treatment of obsessive-compulsive disorder. Drugs, 43: 210-8, 1992.

Zohar J, Insel TR, Zohar-Kadouch RC, Hill JL, Murphy DL. Serotonergic responsivity in obsessive-compulsive disorder: effects of chronic clomipramine treatment. Arch Gen Psychiatry, 45: 167-72, 1988. 